\title{
Ultrasound microbubble-mediated delivery of the siRNAs targeting MDR1 reduces drug resistance of yolk sac carcinoma L2 cells
}

\author{
Yun $\mathrm{He}^{1,2 \dagger}$, Yang Bi ${ }^{2 \dagger}, \mathrm{Yi} \mathrm{Hua}^{1,2}$, Dongyao Liu ${ }^{1,2}$, Sheng Wen ${ }^{1,2}$, Qiang Wang ${ }^{1,2}$, Mingyong $\mathrm{Li}^{1,2}$, Jing Zhu ${ }^{2}$, \\ Tao Lin ${ }^{1,2}$, Dawei He ${ }^{1,2}$, Xuliang Li ${ }^{1,2}$, Zhigang Wang ${ }^{3}$ and Guanghui Wei $\mathrm{i}^{1,2^{*}}$
}

\begin{abstract}
Background: MDR1 gene encoding P-glycoprotein is an ATP-dependent drug efflux transporter and related to drug resistance of yolk sac carcinoma. Ultrasound microbubble-mediated delivery has been used as a novel and effective gene delivery method. We hypothesize that small interfering RNA (siRNA) targeting MDR1 gene (siMDR1) delivery with microbubble and ultrasound can down-regulate MDR1 expression and improve responsiveness to chemotherapeutic drugs for yolk sac carcinoma in vitro.

Methods: Retroviral knockdown vector pSEB-siMDR1s containing specific siRNA sites targeting rat MDR1 coding region were constructed and sequence verified. The resultant PSEB-siMDR1 plasmids DNA were encapsulated with lipid microbubble and the DNA release were triggered by ultrasound when added to culture cells. GFP positive cells were counted by flow cytometry to determine transfection efficiency. Quantitative real-time PCR and western blot were performed to determine the mRNA and protein expression of MDR1. P-glycoprotein function and drug sensitivity were analyzed by Daunorubicin accumulation and MTT assays.

Results: Transfection efficiency of PSEB-siMDR1 DNA was significantly increased by ultrasound microbubblemediated delivery in rat yolk sac carcinoma L2 (L2-RYC) cells. Ultrasound microbubble-mediated siMDR1s delivery effectively inhibited MDR1 expression at both mRNA and protein levels and decreased P-glycoprotein function. Silencing MDR1 led to decreased cell viability and $I_{50}$ of Vincristine and Dactinomycin.

Conclusions: Our results demonstrated that ultrasound microbubble-mediated delivery of MDR1 siRNA was safe and effective in L2-RYC cells. MDR1 silencing led to decreased P-glycoprotein activity and drug resistance of L2-RYC cells, which may be explored as a novel approach of combined gene and chemotherapy for yolk sac carcinoma.
\end{abstract}

Keywords: Yolk sac carcinoma, Ultrasound therapy, RNA interference, Multiple drug resistance gene, Transfection

\section{Background}

Yolk sac carcinoma are the most common malignant germ cell tumors in children, which are commonly found in the ovary, testes, sacrococcygeal areas and the midline of the body [1-4]. This type of germ tumors is aggressive and highly metastatic which can rapidly spread to adjoining tissues through the lymphatic system [5-7]. Meanwhile, clinical data show that yolk sac carcinoma in children

\footnotetext{
* Correspondence: ghwei@cqmu.edu.cn

† Contributed equally

'Department of Urology, The Children's Hospital of Chongqing Medical

University, Chongqing, People's Republic of China

Full list of author information is available at the end of the article
}

have a high recurrence rate. Most of yolk sac carcinoma are refractory to chemotherapy and require a surgical resection of primary tumors and surrounding tissues including germinative glands. While surgical treatment of yolk sac carcinoma can decrease tumor recurrence to certain extent, removal of gonadal tissues may result in longterm physiological and psychological adverse effects in the affected children. Therefore, there is an urgent need to improve the chemotherapy efficacy of yolk sac carcinoma [8-10].

Tumor drug resistance is one of the most important factors which affects the outcomes of chemotherapy [11-13]. It has been well documented that certain, genes 
products, such as multiple drug resistance gene (MDR1), multidrug resistance-associated protein, lung resistance protein, glutathione-S-transferase $\mathrm{Pi}$, contribute to drug resistance [14-17]. Our previous studies showed that MDR1 was the most and highest expressed resistance genes in tissues of yolk sac carcinoma in children. MDR1 gene, also known as ABCB1 (ATP-binding cassette, sub-family $B$, member 1 ) gene, encodes an ATP-dependent drug transporter named permeability glycoprotein (P-glycoprotein). P-glycoprotein is an energy-dependent efflux pump that exports its substrates out of the cells. Many of chemical drugs are substrates of P-glycoprotein. P-glycoprotein plays an important role in drug kinetics, including absorption, distribution, metabolism, and excretion, which limits the accumulation of drugs inside cells and results in drug resistance [18-20]. Yolk sac carcinoma have high expression of MDR1 gene [21], so we hypothesize that small interfering RNA (siRNA) mediated silencing of MDR1 expression would improve the sensitivity of yolk sac carcinoma to chemotherapy drugs.

Ultrasound microbubble-mediated delivery is a novel, nonviral, effective and safe method for delivering drugs or genes to target organs or cells [22-26]. Recent studies have shown that ultrasound microbubble-mediated delivery improves the efficacy of gene transfection and reduces the side effects of other bioactive transfection agents, such as liposome, viral vectors [27]. In this study, we constructed and characterized three effective siRNAs targeting MDR1 gene and used ultrasound microbubblemediated gene delivery method to effectively deliver plasmid DNA into rat yolk sac carcinoma L2 (L2-RYC) cells. Our results demonstrated that the MDR1 siRNAs effectively reduced the multiple-drug resistance of L2-RYC cells. Thus, the reported approach may represent a novel and new method of combined gene silencing and chemotherapy to combat the drug resistance of yolk sac carcinoma.

\section{Methods}

\section{Cell culture and chemicals}

L2-RYC cells were purchased from ATCC (Manassas, VA), and were cultured in complete Dulbecco's modified Eagle's medium (DMEM) supplemented with 10\% fetal bovine serum (FBS, Hyclone, Logan, Utah, USA), $100 \mathrm{units} / \mathrm{ml}$ penicillin, and $100 \mu \mathrm{g} / \mathrm{ml}$ streptomycin at $37^{\circ} \mathrm{C}$ in $5 \% \mathrm{CO}_{2}$.

\section{Construction and validation of plasmids containing siRNAs targeting MDR1}

The pSEB-HUS vector (Additional file 1) containing $\mathrm{H} 1$ and U6 dual-promoter was used to construct the eukaryotic plasmid expressing siRNA targeting MDR1 [28]. Four pairs of oligonucleotides specific for rat MDR1 coding region (Additional file 2) were designed by using Invitrogen Block-iT RNAi Designer software. After annealed in vitro, four double-stranded oligonucleotides cassettes with SfiI cohesive ends were subcloned into the SfiI sites of pSEBHUS vector, resulting in pSEB-siMDR1 plasmids. We transfected four pSEB-siMDR1 plasmids into L2-RYC cells with Lipfectamine 2000 and detected the inhibition efficiency of each siMDR1 by quantitative real-time polymerase chain reaction (qRT-PCR), respectively. After validation, equimolar amounts of pSEB-siMDR1-1, -2 and -3 were pooled and transfected into L2-RYC cells with liposome to detect the inhibition efficiency of MDR1 by qRT-PCR.

\section{Quantitative real-time PCR}

As described previously [29], total RNA was extracted from L2-RYC cells after 2 days transfection using TRIZol reagent (Invitrogen, Carlsbad, CA, USA) and reverse transcripted into single-strand cDNA template with random primer and a reverse transcriptase (Takara, Japan). Primers were 18-20 mers, designed by using Primer 5 program to amplify the 3'-end of rat MDR1 and glyceraldehyde-3phosphate dehydrogenase (GAPDH) genes (Additional file 2). Quantitative RT-PCR reaction was performed as follows: $3 \mathrm{~min}$ at $94^{\circ} \mathrm{C}$ (one cycle), $20 \mathrm{sec}$ at $94^{\circ} \mathrm{C}, 20 \mathrm{sec}$ at $58^{\circ} \mathrm{C}, 20 \mathrm{sec}$ at $72^{\circ} \mathrm{C}$, and reading plate (38 cycles). Raw data of $\mathrm{Ct}$ value for MDR1 in each group was normalized with GAPDH and measured as the fold change.

\section{Preparation of the siMDR1-loaded lipid microbubble}

To prepare lipid microbubble, we mixed $5 \mathrm{mg}$ of dipalmitoyl phosphatidylcholine (Sigma, USA), 2 mg of distearoyl phosphatidyl ethanolamine (Sigma, USA), $1 \mathrm{mg}$ of diphenyl phosphoryl azide (Sigma, USA), and $50 \mu \mathrm{l}$ of glycerol into phosphate buffered saline (PBS) to make the $0.5 \mathrm{ml}$ mixture in a tube. The tube was placed at $40^{\circ} \mathrm{C}$ for $30 \mathrm{~min}$, then filled with perfluoropropane gas (C3F8) and mechanically shaken for $45 \mathrm{sec}$ in a dental amalgamator (YJT Medical Apparatuses and Instruments, Shanghai, China). The pure lipid microbubble was PBS diluted, sterilized by $\mathrm{Co}_{60}$ and stored at $-20^{\circ} \mathrm{C}$. Then, the home-made lipid microbubble were mixed with poly-L-lysine (Sigma, USA), and incubated at $37^{\circ} \mathrm{C}$ for $30 \mathrm{~min}$. Subnatant was removed and washed twice by PBS. Plasmids containing balance mixed siMDR1 plasmids were added and incubated at $37^{\circ} \mathrm{C}$ for $30 \mathrm{~min}$, and washed by PBS twice. This procedure was repeated three times. The siMDR1-loaded lipid microbubble were obtained with an average diameter of $2.82 \pm 0.76 \mu \mathrm{m}$, an average concentration of $8.74 \times 10^{9} /$ $\mathrm{ml}$ and the average potential of $-4.76 \pm 0.82 \mathrm{mV}(\mathrm{n}=5)$. The final concentration of plasmids DNA was $0.5 \mu \mathrm{g} / \mu \mathrm{l}$. 


\section{Trypan blue staining}

Cultured L2-RYC cells in 6-well plates were processed with acoustic intensity of $0.25 \mathrm{~W} / \mathrm{cm}^{2}, 0.5 \mathrm{~W} / \mathrm{cm}^{2}$, $0.75 \mathrm{~W} / \mathrm{cm}^{2}$ and $1 \mathrm{~W} / \mathrm{cm}^{2}$ and irradiation time of $30 \mathrm{sec}$ and $60 \mathrm{sec}$, respectively. Cells were washed, trypsinized and resuspended with PBS with $10^{6}$ cells per milliliter. An equal volume of $0.2 \%$ trypan blue was added to a cell suspension. Then, cell suspensions were incubated at room temperature for $3 \mathrm{~min}$ and loaded into a hemocytometer. With an optical microscope examination, survival cells excluding trypan blue were counted in three separate fields. Survival rate $=$ (number of survival cells $/$ number of total cells) $\times 100 \%$.

\section{Transfection efficiency detected by flow cytometry}

L2-RYC cells were seeded in each well of 24-well culture plates with $5 \times 10^{5}$ cell density and cultured in complete DMEM medium for $24 \mathrm{hrs}$ before transfection. Then cells were treated with pSEB-siMDR1 pooled plasmids alone (group I), plasmids with ultrasound (group II), siMDR1loaded lipid microbubble (group III), siMDR1-loaded lipid microbubble with ultrasound (group IV) and non-plasmid control (group V), respectively. We also set up a lipofection group (Lipo) for comparison of transfection efficiency. Cells in group II and IV were exposed to ultrasound with the radiation frequency of $1 \mathrm{MHz}$, pulse wave, sound intensity of $0.5 \mathrm{~W} / \mathrm{cm}^{2}$ for $30 \mathrm{sec}$ using an ultrasound treatment meter (Institute of Ultrasound Imaging, Chongqing Medical University). Since pSEB-siMDR1 plasmids express green fluorescent protein (GFP), transfected cells were collected and suspended in $1 \mathrm{ml}$ of PBS/BSA buffer at 24 hrs after transfection for flow cytometry as a measurement of transfection efficiency.

\section{Western blot analysis}

Total proteins of L2-RYC cells in each group were extracted by using protein extraction kit (Beyotime, China, at $48 \mathrm{hrs}$ after transfection. Approximately 20 micrograms total proteins per lane were loaded onto a $6 \%$ SDS-PAGE gel. After electrophoretic separation, proteins were transferred to an Immobilon-P membrane. The membrane was blocked with 5\% fat-free skim milk in Tris buffered saline with tween-20 buffer at room temperature for $1 \mathrm{hr}$, and was incubated with anti-MDR1 or anti- $\beta$-actin primary antibody (Santa Cruz Biotechnology, USA), respective, at $4^{\circ} \mathrm{C}$ overnight. After being washed, the membrance was incubated with a secondary antibody conjugated with horseradish peroxidase (HRP) (Santa Cruz Biotechnology, USA) at room temperature for $1 \mathrm{hr}$, followed by extensive wash. The protein of interest was visualized and imaged under the Syngene GBox Image Station by using Luminata Crescendo Western HRP Substrate (Millipore, USA). The expression level of MDR1 proteins was calculated using GBox Image Tools and normalized by $\beta$-actin levels.

\section{Daunorubicin accumulation assay}

Daunorubicin accumulation assay was conducted to determine P-glycoprotein activity [30]. L2-RYC cells were treated as above mentioned in each groups, as well as a blank control. Cells were washed and changed with FBS-free DMEM. Daunorubicin was administered into culture medium at the final concentration of $7.5 \mu \mathrm{g} / \mathrm{ml}$ and the cells were incubated at $37^{\circ} \mathrm{C}$ for $30 \mathrm{~min}$. Cells were then washed with FBS-free DMEM medium again, followed by incubation with Verapamil (Pharmacia Co., Italy) at the final concentration of $10 \mu \mathrm{g} / \mathrm{ml}$ to end the efflux function of P-glycoprotein. Subsequently, cells were washed three times with PBS and the Daunorubicin accumulation was examined under a fluorescence microscope and analyzed by flow cytometry. (FACS Calibur FCM, Becton-Dickinson, San Jose, CA)

\section{MTT assay}

L2-RYC cells in each treated group were seeded into 96well culture plates with $5 \times 10^{3}$ cell density. After incubation in complete DMEM medium for $24 \mathrm{hrs}$, the medium was replaced with FBS-free DMEM containing Vincristine or Dactinomycin at the concentration ranges of $0.1,0.2$, $0.4,0.8,1.6,3.2,6.4,12.8 \mu \mathrm{g} / \mathrm{ml}$ (for Vincristine) and 0.01 , $0.02,0.04,0.08,0.16,0.32,0.64,1.28 \mu \mathrm{g} / \mathrm{ml}$ (for Dactinomycin), respectively. MTT assay was performed at $12 \mathrm{hrs}$ post treatment to determine cell proliferation. Briefly, 20 $\mu \mathrm{l}$ of MTT reagent was added to each well with FBS-free DMEM medium and incubated at $37^{\circ} \mathrm{C}$ for $4 \mathrm{hrs}$. Medium was gently aspirated and replaced by $200 \mu \mathrm{l}$ of DMSO. The 96-well plates were shaken for $10 \mathrm{~min}$ to dissolve the purple crystals and read at $520 \mathrm{~nm}$ in Thermo Scientific Varioskan Flash Spectral Scanning Multimode Reader. Viability of L2-RYC cells in each concentration was calculated as $\mathrm{OD}_{\text {treated }} / \mathrm{OD}_{\text {untreated }} \times 100 \%$. The half maximal inhibitory concentration $\left(\mathrm{IC}_{50}\right)$ was accounted to compare the drug sensitivity among each group.

\section{Statistical analyses}

All data were shown as mean \pm standard deviation (SD). Statistical analyses were performed using SPSS 15.0 software package (SPSS, Inc, Chicago, IL). Mann-Whitney $U$ test was performed to compare results among experimental groups. $P<0.05$ was considered as statistically significant.

\section{Results}

Construction and silencing efficiency of pSEB-siMDR1 plasmids expressing siRNAs against MDR1

We subcloned four pairs of siRNA oligonucleotide cassettes that target rat MDR1 coding region using the previously developed pSOS system [28]. After inserting the cassettes into the pSEB-HUS vector, we were able to amplify and confirm an approximately $300 \mathrm{bp}$ of PCR 
product in the four recombinant pSEB-siMDR1 plasmids using U6 promoter primer and antisense oligonucleotide of siRNA cassettes (Figure 1A). A NotI restriction enzyme site was removed when siRNA oligonucleotide cassettes were inserted into multi cloning sites of pSEBHUS vector. When we used NotI to digest pSEB-siMDR1 plasmids, no about 1300 bp DNA fragment was seen in corrected recombinants compared with pSEB-HUS vector which could be cut out to be about 1300 bp DNA fragment and another large DNA fragment (Figure 1B). Next, we tested the silencing efficiency of different siRNA target sites and found that three of the four pSEBsiMDR1 plasmids transfection decreased the mRNA level of MDR1 in L2-RYC cells. The highest silencing efficiency was observed in the pooled plasmids group (Figure $1 C)$. Therefore, for the following experiment, we chose to use the pooled plasmids to transfect cells.

\section{Cell survival in different ultrasound parameters}

The survival rate of L2-RYC cells in different ultrasound intensities and exposure time was determined by trypan blue staining. Cell survival was more than $95 \%$ when the ultrasound parameters were set as $1 \mathrm{KHz}, 0.25 \mathrm{~W} / \mathrm{cm}^{2}$ or $0.5 \mathrm{~W} / \mathrm{cm}^{2}, 30 \mathrm{sec}$ and pulse wave. Cell death increased significantly when cell were exposed to ultrasound at the intensity of $0.75 \mathrm{~W} / \mathrm{cm}^{2}$ and $1.0 \mathrm{~W} / \mathrm{cm}^{2}$.

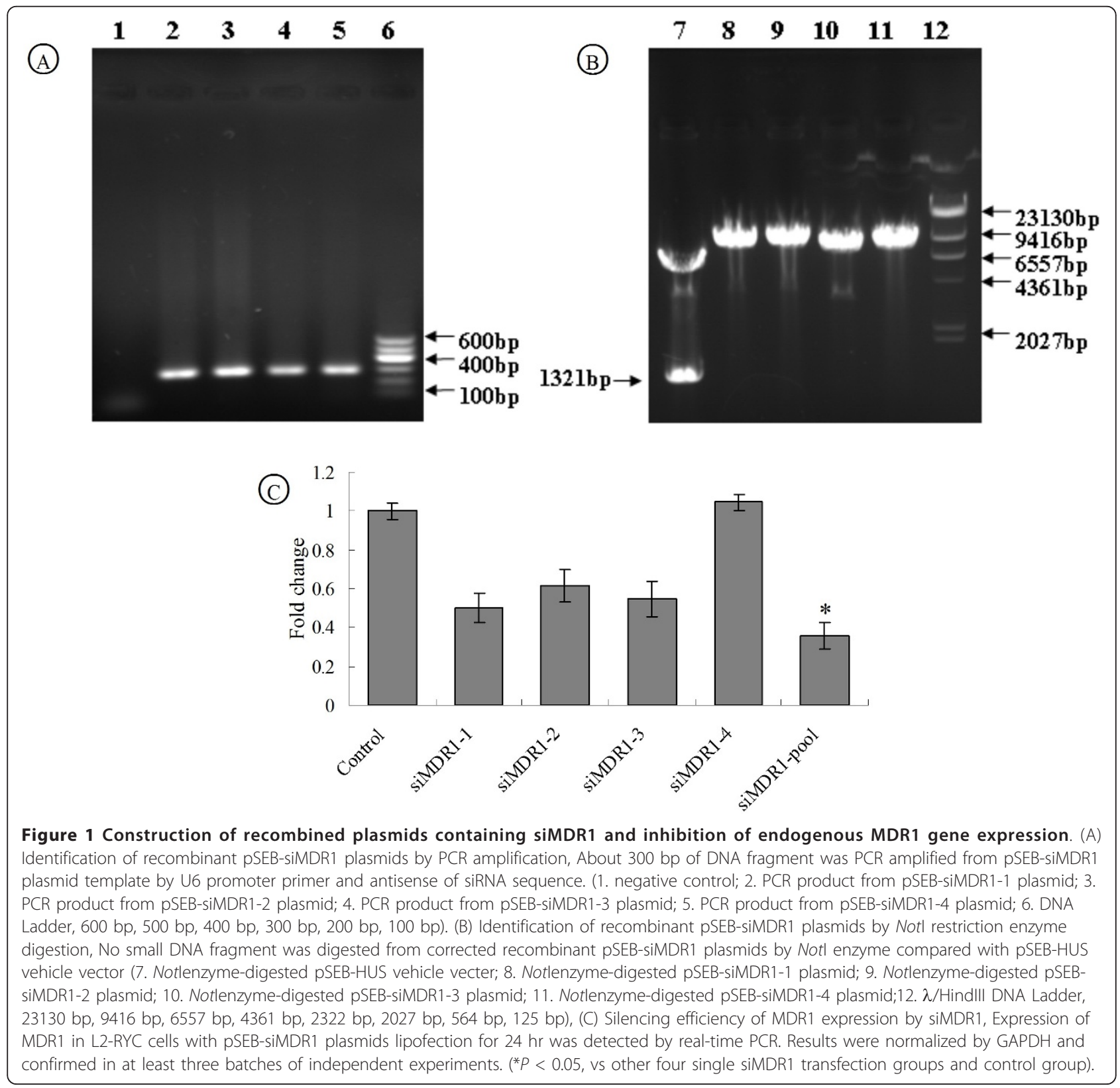


At $0.5 \mathrm{~W} / \mathrm{cm}^{2}$ acoustic intensity, survival rate were $95.22 \pm 1.26 \%$ and $70.16 \pm 3.49 \%$ with $30 \mathrm{sec}$ and $60 \mathrm{sec}$ exposure time, respectively. Nonetheless, our results indicated that ultrasound exposure within a suitable range would not affect cell survival (Table 1).

\section{Transfection efficiency and silencing efficiency of different transfection groups}

Retroviral vector pSEB-HUS contains enhanced GFP code region driven by human EF1 $\alpha$ promoter (hEF1). Thus, GFP expression can reflect the transfection efficiency. Flow cytometry results showed that group I, II, III and IV exhibited very low transfection efficiency $(<8 \%)$ and had no significant difference among these groups. However, approximately $30 \%$ of GFP-positive cells were obtained in group IV (Figure 2A and 2B) which was significantly higher than other experimental groups, including the lipofection group $(P<0.05)$.

The mRNA and protein expression of MDR1 were effectively inhibited in group IV L2-RYC cells. MDR1 expression in other three groups did not decrease when compared with non-plasmid control. There was no significant difference in the mRNA and protein expression of MDR1 among group I, II, III and IV (Figure 3A and 3B). These results demonstrated that siMDR1-loaded microbubble combined with ultrasound-induced burst significantly improved transfection efficiency of plasmid and selected siRNA pool targeting MDR1 could effectively inhibit the MDR1 expression.

\section{Analysis of P-glycoprotein activity with Daunorubicin accumulation assay}

Daunorubicin is a substrate of P-glycoprotein, which has red autofluorescence. Daunorubicin accumulation assay is commonly used to determine the P-glycoprotein activity [31]. We found that only cells in group IV exhibited green fluorescence and had more visible red granular fluorescence in cytoplasm when compared with cells in other groups (Figure 4A). From flow cytometry data (Figure 4B and $4 \mathrm{C}$ ), we found that red fluorescent intensity in group I, II, III and V were 70.85\%, 68.42\%, 70.57\% and 71.72\%, respectively. On the contrary, $90.85 \%$ red fluorescent positive cells were observed in group IV. Thus, our result demonstrated that siMDR1 transfected by ultrasound

Table 1 Cell Viability with different ultrasound intensities and exposure time

\begin{tabular}{ccc}
\hline Intensity $\left(\mathrm{W} / \mathrm{cm}^{2}\right)$ & \multicolumn{2}{c}{ Survival rate (\%) } \\
\cline { 2 - 3 } & $\mathbf{3 0 ~} \mathbf{~}$ & $\mathbf{6 0 ~ \mathbf { ~ }}$ \\
\hline 0.25 & $97.07 \pm 1.14$ & $96.03 \pm 1.51$ \\
0.5 & $95.22 \pm 1.26$ & $70.16 \pm 3.49$ \\
0.75 & $71.25 \pm 3.22$ & $51.75 \pm 4.02$ \\
1 & $37.43 \pm 3.41$ & $23.98 \pm 3.24$ \\
\hline
\end{tabular}

microbubble-mediated delivery could inhibit P-glycoprotein function and increased intracellular accumulation of Daunorubicin in L2-RYC cells.

\section{Sensitivity to chemotherapeutic drugs by MTT assay}

Next, MTT assay was also performed to determine cell viability of L2-RYC cells in vitro. Vincristine and Dactinomycin are two commonly used chemotherapeutic drugs and also substrates of P-glycoprotein. Increased concentrations of two drugs caused reduced cell viability. Cell viability at different concentrations of two drugs and $\mathrm{IC}_{50}$ values were not significantly different among group I, II, III and V (Figure 5A and $5 \mathrm{C}$ ). The $\mathrm{IC}_{50}$ of Vincristine and Dactinomycin were $1.34 \mu \mathrm{g} / \mathrm{ml}$ and $0.11 \mu \mathrm{g} / \mathrm{ml}$ in group IV which were statistically different from other groups $(P<0.05)$ (Figure 5B and 5D). Taken together, our result demonstrated that MDR1 siRNAs were transfected by ultrasound microbubble-mediated delivery could at least partially reverse drug resistance of L2-RYC cells.

\section{Discussion}

Yolk sac carcinoma is a malignant germ cell tumor with aggressive nature in children [5,32]. While chemotherapy is critical to control the metastasis and recurrence of this disease [33], it has been reported that MDR1 expression level is related to the treatment responsiveness and prognosis in chemotherapy of malignant tumors as higher expression of MDR1 maybe lead to the lower efficiency of anti-cancer chemotherapy [20,34]. The multi-drug resistance gene MDR1 encodes an ATP-dependent efflux transporter, P-glycoprotein protein, which protects tissues or cells from environmental toxins and xenobiotics, and prevents tissues or cells from attack of anti-cancer drugs [35-37]. In this study, we investigated whether the downregulation of MDR1 could enhance the drug sensitivity of yolk sac carcinoma in vitro.

Small interfering RNAs (siRNAs) mediated RNA interference is widely used to silence gene expression via transcript degradation in mammalian cells. We chose to use the pSEB-HUS system which was specific for constructing GFP vector containing siRNA. The expression of siRNA can be driven by dual convergent $\mathrm{H} 1$ and U6 promoters and GFP-positive cells post plasmid transfection were easily detected by flow cytometry. Any siRNA can also regulate the expression of unintended targets which have similar silent site of target gene and result in non-specific gene silence. This so-called off-target effect can not only disturb the effect of silence of RNAi but also induce toxic phenotype $[38,39]$. The pooling strategy of multiple target sites has been used to maximize target-gene specificity and efficiency and to minimize non-specific effects [40,41]. In this study, we first identified three effective MDR1 siRNAs from four candidate siRNA sites by qRT-PCR. The three siRNA plasmids were pooled at an equal molar 


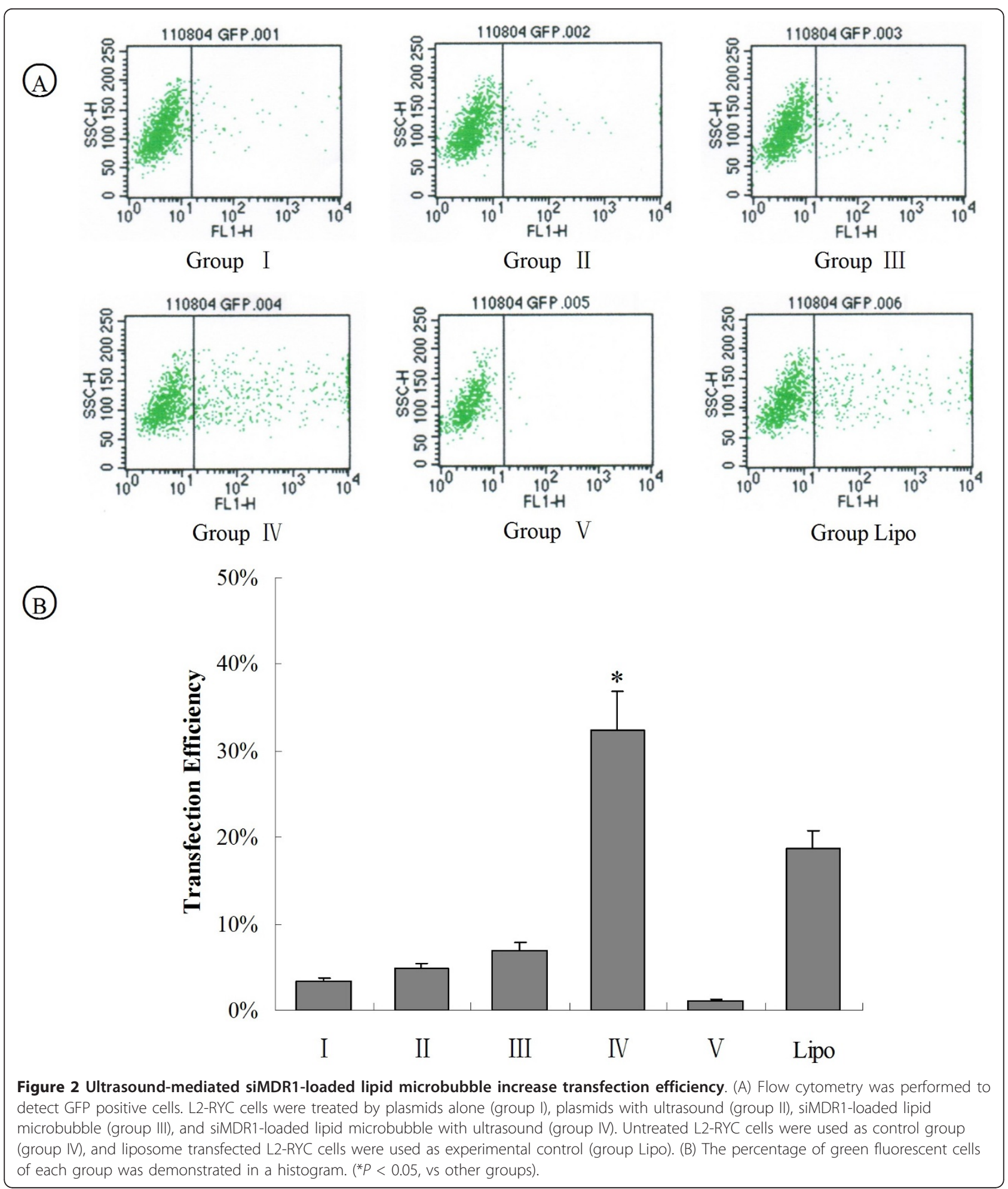

concentrations and transfected into L2-RYC cells. All three siRNAs were specific for MDR1 target gene but at different mRNA degradation sites, so increased the target gene knock-down efficiency of random-designed siRNAs. The decreased concentration of individual siRNAs could reduce potential off-target effects. Our result confirmed that the pooled siRNAs have higher inhibition efficacy than that of potent individual siRNAs.

Effective siRNA DNA delivery into cells and in vivo has been a great challenge for the broad use of RNAi 


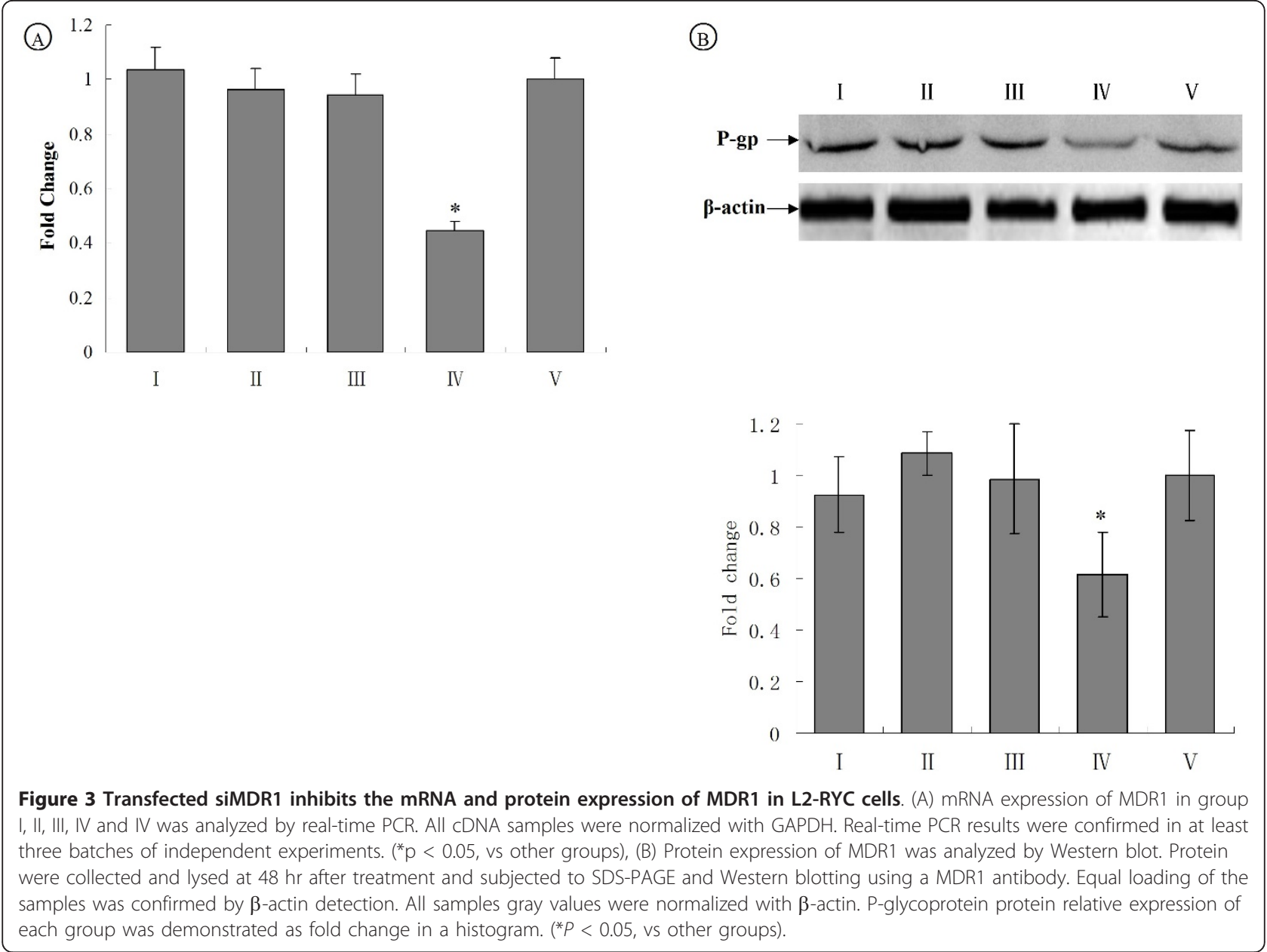

therapeutics. The most commonly used carriers for delivering nucleic acids into mammalian cells are non-viral and viral vectors. Liposome-mediated transfection is simple and powerful, but has cytotoxic side effects [26]. Calcium phosphate co-precipitation has rigorous conditions of transfection and a small range of target cells $[42,43]$. Virus-mediated transfection is high efficient and available to achieve sustainable transgene expression. However the biosafety for in vivo use remains a concern [44]. Recently, ultrasound contrast agents (in a form of microbubble) have been used to deliver gene and drug in vitro and in vivo, providing a new and efficient therapeutic technique [22-25]. Ultrasound microbubble-mediated destruction has been shown to enhance cell membrane permeability and improve gene and drug delivery. It has been shown that ultrasound microbubble-mediated destruction can transfect DNA into a variety of mammalian cells $[22,24,26,45]$. The change of cell membrane permeability is recoverable when ultrasound energy and exposure time are within a suitable range. Thus ultrasound exposure will not cause permanent damage to cells $[45,46]$. We first determined the optimal ultrasound parameters of acoustic intensity and exposure time for L2-RYC cell transfection. When cultured L2-RYC cells were exposed to ultrasound with intensity of $0.75 \mathrm{~W} / \mathrm{cm}^{2}$ and $1 \mathrm{~W} / \mathrm{cm}^{2}$, the survival rates was too low to be used in the study. Although ultrasound with intensity of $0.25 \mathrm{~W} / \mathrm{cm}^{2}$ did not affect cell viability, plasmids DNA delivery into cells was poor. Fortunately, we found out ultrasound with intensity of 0.5 $\mathrm{W} / \mathrm{cm}^{2}$ for $30 \mathrm{~s}$ could effectively transfect plasmids into cells without causing significant amount of cell death. Our previous study on bone marrow mononuclear cells also reported gene delivery by ultrasound with intensity of 0.5 $\mathrm{W} / \mathrm{cm}^{2}$ did not reduce cell viability and not destroy membrane of treated cells [45]. Under the chosen condition, we found that 30\% GFP-positive cells can be achieved by gene transfection using ultrasound microbubble-mediated delivery. This transfection was higher than that of lipofection group and significantly decreased the expression of MDR1 by more than $60 \%$, suggesting that ultrasound microbubble-mediated delivery may be used as an effective gene delivery method.

We determined the effect of silencing MDR1 expression by ultrasound microbubble-mediated siRNA 


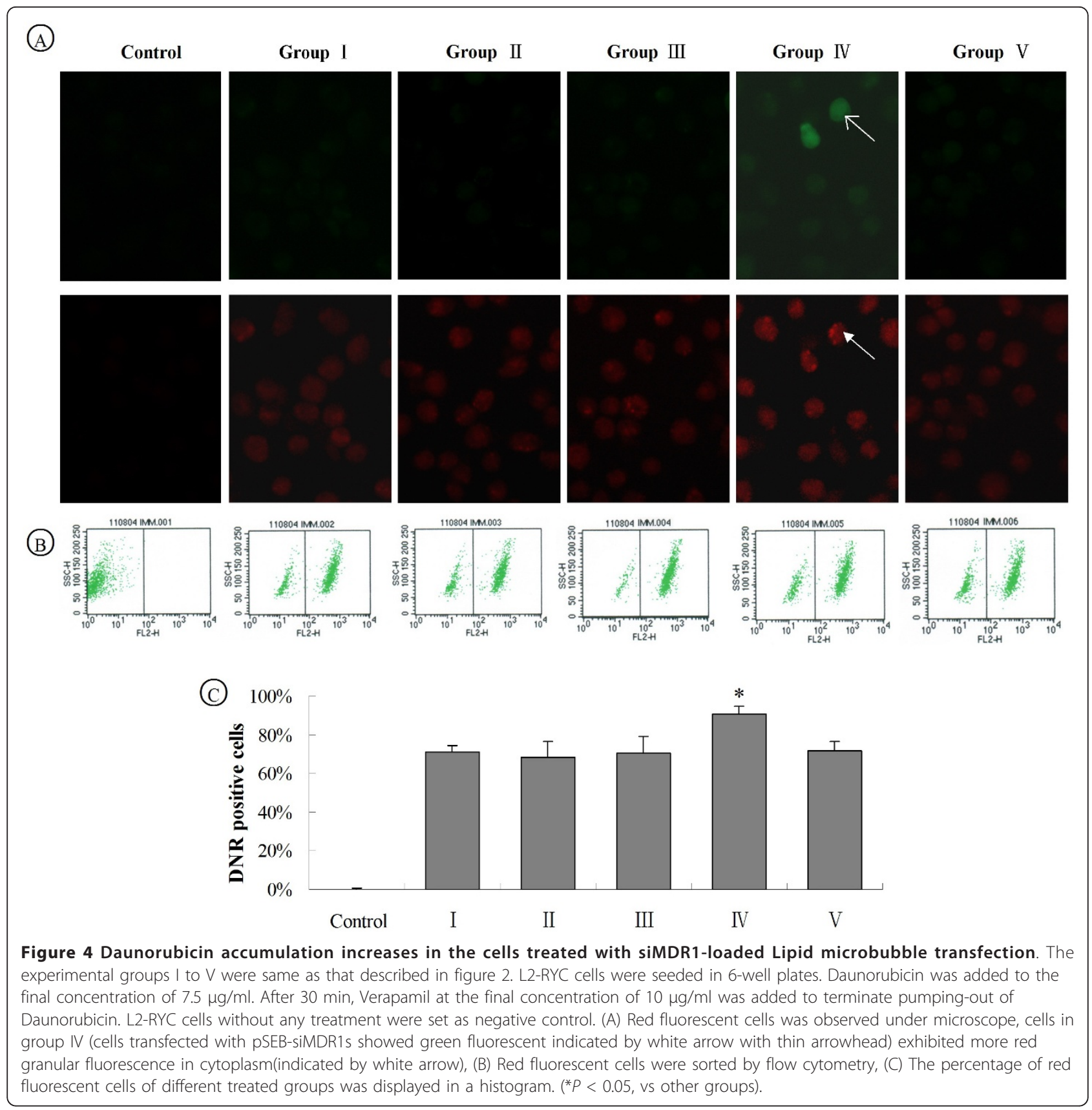

delivery on multidrug resistance of yolk sac carcinamo cells. P-glycoprotein encoded by MDR1 gene is in charge of decreasing drug accumulation in multidrugresistant cells, including tumor cells. Daunorubicin is used in cancer chemotherapy and its subcellular distribution is related to multidrug resistance. Daunorubicin produces red fluorescence with laser excitation at 488 $\mathrm{nm}$, which is readily detected in drug-treated tissues or cells. Thus, Daunorubicin accumulation assay was performed to detect P-glycoprotein activity. Our results indicated that ultrasound microbubble-mediated delivery effectively transferred siMDR1 into L2-RYC cells and led to an increased Daunorubicin accumulation.

Chemotherapeutic drugs are means to combat cancers clinically. However, drug-resistance of tumor cells severely limits therapeutic outcomes. Drug sensitivity can be estimated by tumor cell viability treated with anti-cancer drug. Vincristine and Dactinomycin both of which are most commonly used chemo drugs and also known as substrates of P-glycoprotein. Thus, MTT assay was carried out to detect cell viability at different concentrations of Vincristine and Dactinomycin and to determine 


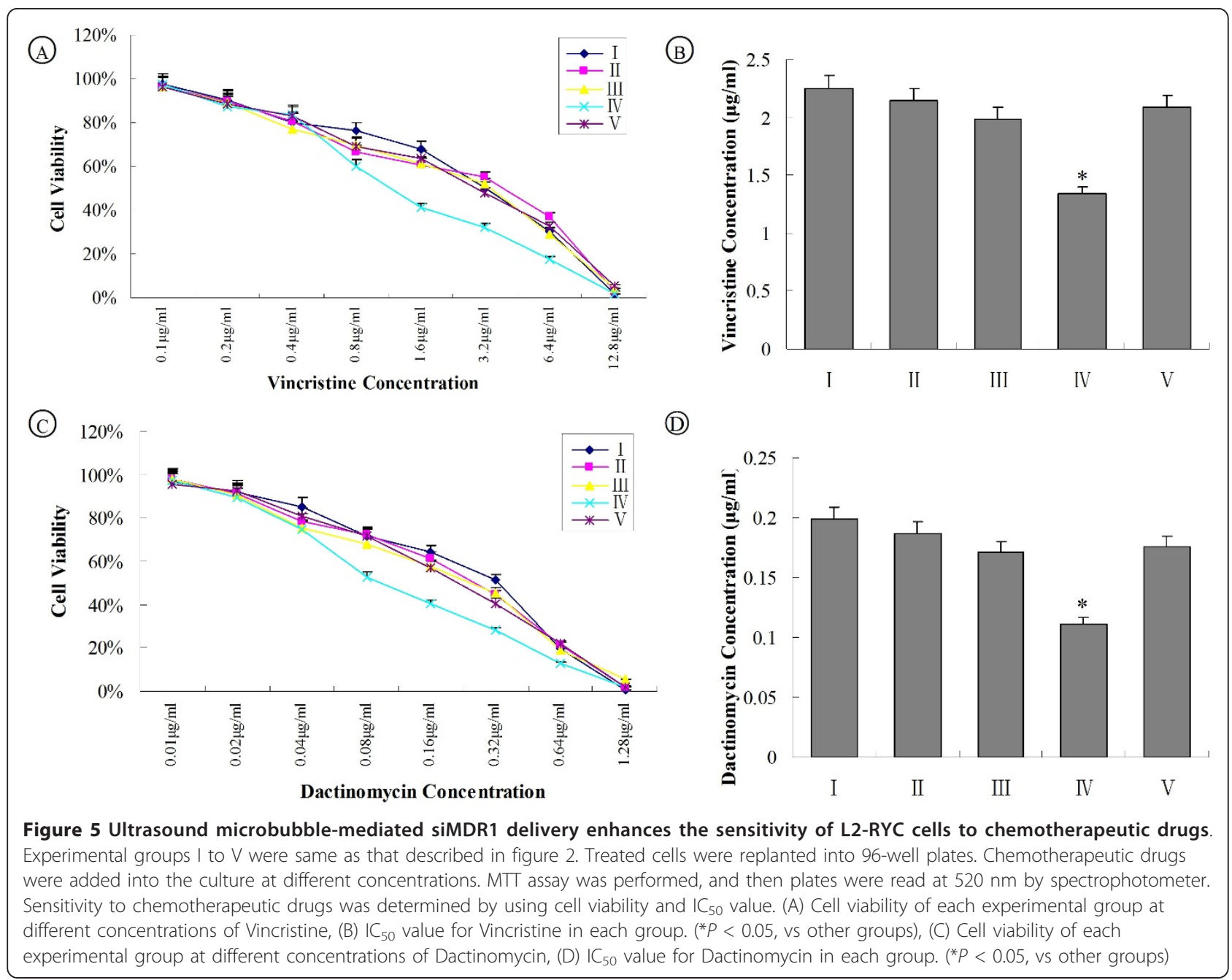

the $\mathrm{IC}_{50}$ ratios of two drugs in each group. Our results revealed that the L2-RYC cells treated with ultrasound microbubble-mediated siMDR1 delivery became more sensitive to anti-cancer drugs. Conceivably, silencing MDR1 should achieve excellent therapeutic efficacy at lower drug dosages so that chemotherapy-associated side effects can be alleviated to certain extends.

\section{Conclusions}

In this study, we constructed plasmids expressing siMDR1 and confirmed their silencing efficiency in L2RYC cells. Ultrasound microbubble-mediated delivery can effectively transfer siMDR1 into L2-RYC cells and lead to inhibition of MDR1 expression and function of P-glycoprotein. Drug sensitivity was also improved by silencing MDR1. Thus, ultrasound microbubblemediated delivery approach is a safe and effective gene transfection method and targeted inhibition method. Our results strongly suggested that combined gene silencing and chemotherapy may be further explored as a novel and potentially efficacious treatment of yolk sac carcinoma.

\section{Additional material}

Additional file 1: Supplementary Figure 1. Map of pSEB-HUS vector and schematic diagram of recombination.

Additional file 2: Supplemental table 1. siRNA targeting MDR1 and PCR primer oligonucleotide sequence.

\section{Abbreviations}

L2-RYC: rat yolk sac carcinoma L2 cells; MDR1: multiple drug resistance gene; P-glycoprotein: permeability glycoprotein; siRNA: small interfering RNA; DMEM: Dulbecco's modified Eagle's medium; FBS: fetal bovine serum; qRTPCR: quantitative real-time Polymerase Chain Reaction; GAPDH:

glyceraldehyde-3-phosphate dehydrogenase; GFP: green fluorescent protein; PBS: phosphate buffered saline; HRP: horseradish peroxidase; $I_{50}$ : half maximal inhibitory concentration

\section{Acknowledgements}

We thank the editors and reviewers for their valuable comments and suggestions which are helpful for improving this manuscript. This work was 
supported by a research grant from the National Natural Science Foundation of China (No.81001030).

\section{Author details}

'Department of Urology, The Children's Hospital of Chongqing Medical University, Chongqing, People's Republic of China. ${ }^{2}$ Key Laboratory of Developmental Diseases in Childhood, Chongqing Medical University, Ministry of Education, Chongqing, People's Republic of China. ${ }^{3}$ Institute of Ultrasound Image, the Second Affiliated Hospital of Chongqing Medical University, Chongqing, People's Republic of China.

\section{Authors' contributions}

$\mathrm{YH}$ and $\mathrm{YB}$ carried out the experiments and drafted the manuscript; $\mathrm{DL}$ and SW participated in cell culture; ML and QW participated in flow cytometry; $\mathrm{YH}$ and JZ executed statistical analyses; ZW instructed the ultrasound technology; $\mathrm{TL}, \mathrm{DH}, \mathrm{XL}$ and $\mathrm{GW}$ designed the project and drafted the manuscript. All authors read and approved the final manuscript.

\section{Competing interests}

The authors declare that they have no competing interests.

Received: 23 August 2011 Accepted: 28 October 2011

Published: 28 October 2011

\section{References}

1. Even C, Lhommé C, Duvillard P, Morice P, Balleyguier C, Pautier P, Troalen F, de La Motte Rouge T: Ovarian yolk sac tumour: general review. Bull Cancer 2011, 98:963-75.

2. Merchant A, Stewart RW: Sacrococcygeal yolk sac tumor presenting as subcutaneous fluid collection initially treated as abscess. South Med J 2010, 103:1068-1070

3. Pasternack T, Shaco-Levy R, Wiznitzer A, Piura B: Extraovarian pelvic yolk sac tumor: case report and review of published work. J Obstet Gynaecol Res 2008, 4:739-744.

4. Tsugu H, Oshiro S, Ueno Y, Abe H, Komatsu F, Sakamoto S, Matsumoto S, Nabeshima K, Fukushima T, Inoue T: Primary yolk sac tumor within the lateral ventricle. Neurol Med Chir (Tokyo) 2009, 49:528-531.

5. Unal O, Beyazal M, Avcu S, Akbayram S, Akgun C: Metastasis of testicular yolk sac tumor to cauda equina. Fetal Pediatr Pathol 2011, 30:150-155.

6. Bayar GR, Gulses A, Sencimen M, Aydintug YS, Arpaci F, Gunhan O: Oral metastasis of the mediastinal germ cell tumor (yolk sac). J Craniofac Surg 2010, 21:1828-1830.

7. Chen $\mathrm{CJ}, \mathrm{Hsu} \mathrm{HT}$, Yen $\mathrm{HH}$ : An unusual cause of upper gastrointestinal bleeding: Gastric yolk sac tumor with a large retroperitoneal metastasis. Gastroenterology 2010, 139:1098-1427.

8. Low JJ, Perrin LC, Crandon AJ, Hacker NF: Conservative surgery to preserve ovarian function in patients with malignant ovarian germ cell tumors: A review of 74 cases. Cancer 2000, 89:391-398.

9. Weinberg LE, Lurain JR, Singh DK, Schink JC: Survival and reproductive outcomes in women treated for malignant ovarian germ cell tumors Gynecol Oncol 2011, 121:285-289.

10. Shibata K, Umezu T, Sakurai M, Kajiyama H, Yamamoto E, Ino K, Nawa A, Kikkawa F: Establishment of cisplatin-resistant ovarian yolk sac tumor cells and investigation of the mechanism of cisplatin resistance using this cell line. Gynecol Obstet Invest 2011, 71:104-111.

11. Garrido W, Muñoz M, San Martín R, Quezada C: FK506 confers chemosensitivity to anticancer drugs in glioblastoma multiforme cells by decreasing the expression of the multiple resistance-associated protein1. Biochem Biophys Res Commun 2011, 411:62-68.

12. Carmo CR, Lyons-Lewis J, Seckl MJ, Costa-Pereira AP: A novel requirement for Janus kinases as mediators of drug resistance induced by fibroblast growth factor-2 in human cancer cells. PLoS One 2011, 6:e19861.

13. Peigñan L, Garrido W, Segura R, Melo R, Rojas D, Cárcamo JG, San Martín R, Quezada C: Combined use of anticancer drugs and an inhibitor of multiple drug resistance-associated protein-1 increases sensitivity and decreases survival of glioblastoma multiforme cells in vitro. Neurochem Res 2011, 36:1397-1406.

14. Shi H, Lu D, Shu Y, Shi W, Lu S, Wang K: Expression of multidrug resistance-related proteins $\mathrm{p}$-glycoprotein, glutathione-s-transferases, topoisomerase-Il and lung resistance protein in primary gastric cardiac adenocarcinoma. Hepatogastroenterology 2008, 55:1530-1536.
15. He SM, Li R, Kanwar JR, Zhou SF: Structural and functional properties of human multidrug resistance protein 1 (MRP1/ABCC1). Curr Med Chem 2011, 18:439-481.

16. Zhang B, Liu M, Tang HK, Ma HB, Wang C, Chen X, Huang HZ: The expression and significance of MRP1, LRP, TOPO॥ $\beta$, and BCL2 in tongue squamous cell carcinoma. J Oral Pathol Med, published online: $28 \mathrm{JUL}$ 2011

17. Hu WQ, Peng CW, Li Y: The expression and significance of Pglycoprotein, lung resistance protein and multidrug resistanceassociated protein in gastric cancer. J Exp Clin Cancer Res 2009, 28:144.

18. Váradi A, Szakács G, Bakos E, Sarkadi B: P glycoprotein and the mechanism of multidrug resistance. Novartis Found Symp 2002, 243:54-65.

19. Weinstein RS, Kuszak JR, Kluskens LF, Coon JS: P-glycoproteins in pathology: the multidrug resistance gene family in humans. Hum Pathol 1990, 21:34-48.

20. Oshikata A, Matsushita T, Ueoka R: Enhancement of drug efflux activity via MDR1 protein by spheroid culture of human hepatic cancer cells. J Biosci Bioeng 2011, 111:590-593.

21. Eid H, Bodrogi I, Csókay B, Oláh E, Bak M: Multidrug resistance of testis cancers: the study of clinical relevance of P-glycoprotein expression. Anticancer Res 1996, 16:3447-3452.

22. Wang J, Zheng Y, Yang F, Zhao P, Li H: Survivin small interfering RNA transfected with a microbubble and ultrasound exposure inducing apoptosis in ovarian carcinoma cells. Int J Gynecol Cancer 2010, 20:500-506.

23. Suzuki J, Ogawa M, Takayama K, Taniyama Y, Morishita R, Hirata Y, Nagai R, Isobe M: Ultrasound-microbubble-mediated intercellular adhesion molecule-1 small interfering ribonucleic acid transfection attenuates neointimal formation after arterial injury in mice. J Am Coll Cardiol 2010, 55:904-913.

24. Luo J, Zhou X, Diao L, Wang Z: Experimental research on wild-type p53 plasmid transfected into retinoblastoma cells and tissues using an ultrasound microbubble intensifier. J Int Med Res 2010, 38:1005-1015.

25. Chen ZY, Liang K, Qiu RX: Targeted gene delivery in tumor xenografts by the combination of ultrasound-targeted microbubble destruction and polyethylenimine to inhibit survivin gene expression and induce apoptosis. J Exp Clin Cancer Res 2010, 29:152.

26. Dang SP, Wang RX, Qin MD, Zhang Y, Gu YZ, Wang MY, Yang QL, Li XR, Zhang $X G$ : A novel transfection method for eukaryotic cells using polyethylenimine coated albumin microbubbles. Plasmid 2011, 66:19-25.

27. Wang Y, Zhou J, Zhang Y, Wang X, Chen J: Delivery of TFPI-2 using SonoVue and adenovirus results in the suppression of thrombosis and arterial re-stenosis. Exp Biol Med (Maywood) 2010, 235:1072-1081.

28. Luo Q, Kang Q, Song WX, Luu HH, Luo X, An N, Luo J, Deng ZL, Jiang W,

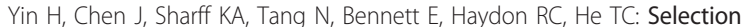
and validation of optimal siRNA target sites for RNAi-mediated gene silencing. Gene 2007, 1-2:160-169.

29. He Y, Zhang WY, Gong M, Huang JY, Tang N, Feng T, Wei GH, He TC, Bi Y: Low serum concentration facilitates the differentiation of hepatic progenitor cells. Saudi Med J 2011, 32:128-134.

30. Nabekura T, Yamaki T, Hiroi T, Ueno K, Kitagawa S: Inhibition of anticancer drug efflux transporter P-glycoprotein by rosemary phytochemicals. Pharmacol Res 2010, 61:259-263.

31. Nabekura T, Yamaki T, Kitagawa S: Effects of chemopreventive citrus phytochemicals on human P-glycoprotein and multidrug resistance protein 1. Eur J Pharmacol 2008, 600:45-49.

32. Shah JP, Kumar S, Bryant CS, Ali-Fehmi R, Malone JM Jr, Deppe G, Morris RT: A population-based analysis of 788 cases of yolk sac tumors: A comparison of males and females. Int J Cancer 2008, 123:2671-2675.

33. de La Motte Rouge T, Pautier P, Duvillard P, Rey A, Morice P, Haie-Meder C, Kerbrat $P$, Culine S, Troalen F, Lhommé $C$ : Survival and reproductive function of 52 women treated with surgery and bleomycin, etoposide, cisplatin (BEP) chemotherapy for ovarian yolk sac tumor. Ann Oncol 2008 19:1435-1441.

34. Mhaidat NM, Alshogran OY, Khabour OF, Alzoubi KH, Matalka II, Haddadin WJ, Mahasneh 1O, Aldaher AN: Multi-drug resistance 1 genetic polymorphism and prediction of chemotherapy response in Hodgkin's Lymphoma. J Exp Clin Cancer Res 2011, 30:68.

35. Mizutani T, Masuda M, Nakai E, Furumiya K, Togawa H, Nakamura $Y$, Kawai Y, Nakahira K, Shinkai S, Takahashi K: Genuine functions of Pglycoprotein (ABCB1). Curr Drug Metab 2008, 9:167-174. 
36. Maier P, Fleckenstein K, Li L, Laufs S, Zeller WJ, Baum C, Fruehauf S, Herskind C, Wenz F: Overexpression of MDR1 using a retroviral vector differentially regulates genes involved in detoxification and apoptosis and confers radioprotection. Radiat Res 2006, 166:463-473.

37. Achard-Joris M, Bourdineaud JP: Heterologous expression of bacterial and human multidrug resistance proteins protect Escherichia coli against mercury and zinc contamination. Biometals 2006, 19:695-704.

38. Jackson AL, Linsley PS: Recognizing and avoiding siRNA off-target effects for target identification and therapeutic application. Nat Rev Drug Discov 2010, 9:57-67.

39. Caffrey DR, Zhao J, Song Z, Schaffer ME, Haney SA, Subramanian RR, Seymour AB, Hughes JD: siRNA Off-Target Effects Can Be Reduced at Concentrations That Match Their Individual Potency. PLoS One 2011, 6: e21503.

40. Parsons BD, Schindler A, Evans DH, Foley E: A direct phenotypic comparison of siRNA pools and multiple individual duplexes in a functional assay. PLoS One 2009, 4:e8471.

41. Hsieh AC, Bo R, Manola J, Vazquez F, Bare O, Khvorova A, Scaringe S, Sellers WR: A library of siRNA duplexes targeting the phosphoinositide 3kinase pathway: determinants of gene silencing for use in cell-based screens. Nucleic Acids Res 2004, 32:893-901.

42. Wang $X$, Ito A, Li X, Sogo Y, Oyane A: Signal molecules-calcium phosphate coprecipitation and its biomedical application as a functional coating. Biofabrication 2011, 3:022001.

43. Sun B, Tran KK, Shen H: Enabling customization of non-viral gene delivery systems for individual cell types by surface-induced mineralization. Biomaterials 2009, 30:6386-6393.

44. Posadas I, Guerra FJ, Ceña V: Nonviral vectors for the delivery of small interfering RNAs to the CNS. Nanomedicine (Lond) 2010, 5:1219-1236.

45. Guo Z, Hong S, Jin X, Luo Q, Wang Z, Wang Y: Study on the multidrug resistance 1 gene transfection efficiency using adenovirus vector enhanced by ultrasonic microbubbles in vitro. Mol Biotechnol 2011, 48:138-146.

46. ter Haar GR: Ultrasonic contrast agents: safety considerations reviewed. Eur J Radiol 2002, 41:217-221.

doi:10.1186/1756-9966-30-104

Cite this article as: He et al:: Ultrasound microbubble-mediated delivery of the siRNAs targeting MDR1 reduces drug resistance of yolk sac carcinoma L2 cells. Journal of Experimental \& Clinical Cancer Research 2011 30:104.

\section{Submit your next manuscript to BioMed Central and take full advantage of:}

- Convenient online submission

- Thorough peer review

- No space constraints or color figure charges

- Immediate publication on acceptance

- Inclusion in PubMed, CAS, Scopus and Google Scholar

- Research which is freely available for redistribution 